\title{
Molecular tracking: A concept for side-draw distillation column design
}

Nazemzadeh, Nima; Udugama, Isuru A.; Karcz, Adam Paul; Andersson, Martin P.; Abildskov, Jens; Mansouri, Seyed Soheil

Published in:

AIChE Journal

Link to article, DOI:

10.1002/aic. 17070

Publication date:

2021

Document Version

Peer reviewed version

Link back to DTU Orbit

Citation (APA):

Nazemzadeh, N., Udugama, I. A., Karcz, A. P., Andersson, M. P., Abildskov, J., \& Mansouri, S. S. (2021). Molecular tracking: A concept for side-draw distillation column design. AlChE Journal, e17070.

https://doi.org/10.1002/aic.17070

\section{General rights}

Copyright and moral rights for the publications made accessible in the public portal are retained by the authors and/or other copyright owners and it is a condition of accessing publications that users recognise and abide by the legal requirements associated with these rights.

- Users may download and print one copy of any publication from the public portal for the purpose of private study or research.

- You may not further distribute the material or use it for any profit-making activity or commercial gain

- You may freely distribute the URL identifying the publication in the public portal

If you believe that this document breaches copyright please contact us providing details, and we will remove access to the work immediately and investigate your claim. 


\title{
Molecular tracking: A concept for side-draw distillation column design
}

Nima Nazemzadeh, Isuru A. Udugama, Adam Paul Karcz, Martin P. Andersson, Jens Abildskov, Seyed Soheil Mansouri*

Department of Chemical and Biochemical Engineering, Søltofts Plads, Building 228A, Technical University of Denmark, Kgs. Lyngby DK-2800, Denmark

*seso@kt.dtu.dk

\begin{abstract}
A simple approach is introduced to locate a side-draw tray for ternary and multi-component mixtures with middle boiling component(s) present in the system at trace levels. The concept is based on a probability function defined by the thermodynamic properties of the system. The advantage of this method over existing methods is the ability to quickly and efficiently provide a feasible configuration of the distillation unit without relying on rigorous optimization or trial and error approaches. Moreover, it provides an intuitive understanding of the movements of the middle boiling components in the column.
\end{abstract}

\section{Keywords}

molecular tracking, side-draw distillation, design, multi-component distillation, column duty

This article has been accepted for publication and undergone full peer review but has not been through the copyediting, typesetting, pagination and proofreading process which may lead to differences between this version and the Version of Record. Please cite this article as doi: 10.1002/aic.17070 


\section{- Introduction}

Separation of mixtures through distillation is well-established in chemical, petrochemical, and biopharmaceutical industries ${ }^{1}$. Distillation (often the benchmark method) may well consume about $60 \%$ of the chemical plant energy demand ${ }^{2}$. Moreover, distillation units account for approximately $3 \%$ of U.S. national energy consumption ${ }^{3}$. Considering that more than 40,000 distillation units are operating presently, even slight reductions in energy consumption can be significant. Process intensification in distillation can be realized by combining different units into multi-functional units ${ }^{4}$. A few examples of process intensification are side-draw distillation, cyclic distillation, reactive distillation, and heat integrated distillation units. A side-draw distillation unit can be considered as a simple form of process intensification at the unit operation level. Improvements may be made at different stages of design, operation, and/or control. However, improvements at the design stage may greatly facilitate operation and control. Thus, developing a novel approach for the design of a distillation unit leading to reduced energy demand of the system has great scope. Integration of process design and control has been carried out on various intensified distillation units such as cyclic distillation ${ }^{5-7}$, and reactive distillation ${ }^{8-10}$. In some cases, the integration of process design and control has been led to a tool ${ }^{11,12}$ that solves problems 
addressing integrated process design and control. A proper model will be helpful to solve an integrated design and control for the side-draw distillation unit as well.

A parametric study ${ }^{13}$ argues that for a ternary mixture in which high purity of the middle product is not required, a side-draw distillation unit, as represented in Fig. 1, should be considered as one possible configuration for the desired separation task ${ }^{13}$.

Different methods have been described to design side-draw distillation columns. These include geometric ${ }^{14}$, shortcut ${ }^{15}$, driving force-based ${ }^{16}$ and optimization-based methods ${ }^{17}$. Geometric methods use residue curve maps to determine the design configuration of the column. However, the location of side-draw must be chosen, which may not necessarily be located on the optimum tray in terms of column duty ${ }^{14}$. Shortcut methods for side-draw distillation columns can provide an accurate estimation of the number of trays, side-draw composition, and vapor rate for mixtures with ideal or nearly ideal behavior ${ }^{15}$. A driving force-based method used by ${ }^{16}$ uses the concept of driving force to simultaneously find the optimum location of the feed and side-draw corresponding to minimum column utility exchange, but the method has not been used for ternary mixtures with trace concentrations of middle boiling components. However, optimization-based methods are accurate and capable of determining the design configuration of complex distillation tasks like side-draw distillation. Nonetheless, these methods imply complex mathematical formulations and rely on good initial guesses of the column configuration, as this may considerably affect the time and effectiveness of mathematical optimization ${ }^{17,18}$. A comparison is planned to be carried out 
between the developed algorithm in this paper and optimization-based problems in future studies. However, the authors believe that configurations proposed by molecular tracking can be used as an initial input on optimization algorithms to reduce the computational time required for rigorous optimization-based problems.

Here we explore a simple method for side-draw tray identification for ternary and multi-component mixtures in which the middle boiling component(s) is at infinite dilution. It is intended to find an overall configuration of such units, including the number of theoretical trays, feed, and side-draw location, to minimize the operating expenditures (OPEX) of the system, as well as the time required for the design procedure.

The central concept is that of molecular tracking of Clifford Maat, as proposed a few years ago 1,19. The concept of molecular tracking predicts single-molecule distribution inside the system, based on a probability function of a molecule moving up- or downward from a theoretical stage, within either vapor phase or liquid phase.

Presumably, in a simple distillation of a ternary mixture with only two distillate and bottom products, the most volatile component easily flows towards the distillate product stream, while the least volatile component will be directed to the bottom stream. However, the middle boiling component may be accumulated somewhere between the two product streams. The tray, in which the middle boiling component is accumulated is presumably the best location of the side-draw with the maximum concentration of such molecules in the system to ensure minimum top and bottom 
product losses. A new approach is proposed in this work, which is to find the side-draw location corresponding to the minimum column reboiler duty. The column required for separation of a ternary mixture with impurity amounts of middle boiling component is designed for the key components in the system, primarily based on the driving force concept. Therefore, the impurity is introduced in the system, and the proper location of side-draw is to be found by using the concept of molecular tracking.

\section{- Molecular tracking}

Molecular tracking is a concept capable of predicting distributions of molecular positions (and even paths) inside a column. The paths estimated based on the concept of molecular tracking are estimations of the real molecular pathways that a single molecule follows in a column. Molecular tracking is based on a probability function, which determines the expectation of single-molecule movement to an upper tray in the vapor phase or a lower tray in the liquid phase inside the system. A mathematical expression of the probability of a molecule moving up with the vapor phase is expressed by Eq. (1). With such estimates it is possible to follow a single molecule through a distillation unit, using a random generator function repeatedly and combining its value with the corresponding probability value. This process is continued until the molecule leaves the unit either from the distillate or bottom stream.

$$
\beta_{i}^{n}=\frac{V^{n} y_{i}^{n}}{V^{n} y_{i}^{n}+L^{n} x_{i}^{n}}
$$


where $n$ represents the stage number of the unit, and $V$ and $L$ denote vapor and liquid molar flows in the system, respectively.

It is more convenient to employ $K$-values instead of vapor and liquid compositions in the expressions, giving:

$$
\beta_{i}^{n}=\frac{V^{n} K_{i}^{n}}{V^{n} K_{i}^{n}+L^{n}} \quad ; \quad K_{i}^{n}=\frac{y_{i}^{n}}{x_{i}^{n}}
$$

The above expression may undergo some slight modifications depending on the stage it applies to. For example, in case of a total condenser, the probability value should be determined by dividing the liquid reflux rate to the distillate flowrate.

The middle boiling component moves inside the column and accumulates somewhere between the top and bottom trays in the absence of a side-draw. This component will fluctuate around that tray without leaving the system.

Fluctuation around a tray means that the molecules are indifferent to moving in either direction. Therefore, the probability of the molecule to prefer the vapor phase and move into the upper tray or the liquid phase and move towards the lower trays are the same, nearly 50\%. At this point the molecules have the same tendency to prefer either phase, that is, the separation is not effective in that stage, so that stage is the best-suited location of a side-draw.

The light key (Fig. ) tends to move to the top of the column in a few steps, whereas the heavy key tends to move in the opposite direction ${ }^{1}$. However, the middle boiling component moves towards 
either the top or the bottom of the column, and it fluctuates around a specific tray. In molecular tracking, a component is tracked from the moment it enters the column from feed location. In order to track the molecule, a random generator function is used. The random number is then compared with the probability value of the component on a tray. If the random number lies in $\left(0, \beta_{i}^{n}\right)$, the molecule is considered to move to the vapor phase and the upper tray. Otherwise, it is considered to have the tendency to move to the liquid phase and the lower tray. This operation is repeated until the molecule leaves the column from either distillate or bottom stream. The molecular pathways generated from such operation is represented in Fig. 2. A pass (hit) counter is defined to count the times a molecule passes each tray. By applying this operation on a ternary mixture in a column with only distillate and bottom product streams, the molecular pathways are generated as represented in Fig. 2(a). The volatile component moves directly to the distillate. Hence, the number of hits is the highest at the first tray from the top of the column (Fig. 2(b)). While it is the opposite for the heavy component (Fig. 2(b)). However, the middle boiling component has a tendency to spend several steps in the middle of the column before leaving the unit from either distillate or bottom product. From a thermodynamic point of view, the tray with the maximum number of passes (hits) is the most probable location of the side-draw (Fig. 2(c)). This location is the tray in which the probability of the middle boiling component is equal to $50 \%$ considering the molecular tracking concept.

\section{- Methodology}


A methodology for designing a side-draw distillation unit of a multi-component mixture, wherein the middle boiling component(s) is at infinite dilution, is developed. However, in mixtures where the middle boiling component is significant, molecular tracking is able to find the side-draw location in a design space (given the number of theoretical trays and feed tray). While near-ideal mixtures are used for demonstration, the method is not limited to (near) ideal mixtures. In fact, it applies as well to non-ideal mixtures. The method combines the driving force approach ${ }^{16}$ and the concept of molecular tracking; however, the molecular tracking concept is not limited to driving force-based designs. The general overview of the framework is provided in Fig. 3. The method is divided into two sections for the ease of following the procedure.

\section{- Binary distillation column design}

The design of a binary distillation can be easily carried out by using different graphical or optimization-based methods including McCabe-Thiele, Ponchon-Savarit, and driving force-based methods. The design algorithm used in this section is based on a driving force-based concept

described by Lopez-Arenas et al. ${ }^{20}$, which claims to determine an optimal design configuration by minimizing the column duty. This method is employed to determine a configuration for separating the binary mixture of the key components. This configuration has the minimum column duty for the theoretical binary mixture of key components. However, other methods can be used to design the binary column for key components in the mixture. By choosing a different design method in Algorithm 1, molecular tracking is still able to find the optimum side-draw location in the given 
design space. However, the final design configuration will be different. The algorithm is fully described through Algorithm 1.

\section{Algorithm 1}

Step 1. Generate or retrieve VLE data for the key components in the mixture.

Step 2. Calculate the driving force of key components and plot the driving force diagram as a function of liquid light key composition.

Step 3. Locate the maximum driving force and its corresponding composition.

Step 4. Specify the purity requirements.

Step 5. Calculate the minimum required reflux ratio for this separation task based on the following equation.

$$
\frac{1}{1+R R_{\min }}=\frac{D_{y}}{x_{D}-D_{x}}
$$

$R R_{\min }$ is the minimum reflux ratio required for the separation task, $D_{x}$ and $D_{y}$ are the liquid composition and its corresponding maximum driving force, and $x_{D}$ is the unit purity specification of the distillate.

Step 6. Specify the ratio of the actual and minimum reflux ratio. Calculate the actual reflux ratio based on that value and the minimum reflux ratio calculated in Step 5.

$$
C C=\frac{R R}{R R_{\min }}
$$


$\mathrm{RR}$ is the actual reflux ratio of the separation task.

Step 7. Determine the feed quality required for the reflux ratio acquired in Step 6 based on the following equation.

$$
q=\frac{z_{F}-D_{x}}{D_{y}}
$$

Here, $\mathrm{q}$ is the vapor quality of the feed and $z_{F}$ is the light key composition of the feed stream.

Step 8. Draw feed, rectifying, and stripping operating lines in a VLE diagram based on the McCabe-Thiele method to find the total number of stages and feed location.

Step 9. Determine the temperature and composition profile of the unit regarding the $T-x y$ and McCabe-Thiele diagram.

Step 10. Based on McCabe-Thiele assumption of constant vapor and liquid internal flows, calculate these variables based on a simple material balance over rectifying and stripping sections.

$$
\begin{gathered}
V=D(1+R R) \\
L=V-D \\
V^{\prime}=V-q F \\
L^{\prime}=L+(1-q) F
\end{gathered}
$$


$V$ and $L$ are the vapor and liquid internal flowrate of rectifying section, while $V^{\prime}$ and $L^{\prime}$ are the internal flowrate of stripping section. $F$ is the feed flowrate, $D$ and $B$ are distillate and bottom stream flowrates.

\section{- Find side-draw location using molecular tracking}

Next, we locate the side-draw tray, such that the reboiler duty is the minimum in that specific design space, given the unit configuration of the previous section of the framework. The idea is now to introduce the middle boiling component (impurity) as the third component in the system. First, one must find the most proper location of the side-draw, based on the probability function. This is described through Algorithm 2.

\section{Algorithm 2}

Step 1. Calculate the $K$-value for this component based on the thermodynamic model used in Algorithm 1, step 1 to generate the VLE data. A phi-phi approach is used in this study to calculate the $K$-values of the middle boiling component (see Eq. (10)), since the VLE data is generated based on the Peng-Robinson equation of state.

$$
K_{M B}=\frac{y_{M B}}{x_{M B}}=\frac{\hat{\varphi}_{M B}^{l \infty}}{\hat{\varphi}_{M B}^{v \infty}}
$$


MB denotes the middle boiling component, and $K$ is the $K$-value. $\hat{\varphi}_{i}{ }^{\infty}$ is the fugacity coefficient at infinite dilution. In order to calculate the fugacity coefficient, the PengRobinson equation of state is used for a ternary mixture while the middle boiling component concentration is zero.

Step 2. Calculate the probability profile for the middle component based on the following equation.

$$
\beta_{M B}=\frac{K_{M B} V}{K_{M B} V+L}
$$

Step 3. Find the trays where the probability value calculated in Step 2 is $50 \%$.

Step 4. If only one tray is found in Step 3, the side-draw must be located on that tray. Else, go to step 5 .

Step 5. Simulate the column by fixing the two key components purity requirements. Locate the feed on the tray determined from Algorithm 1 (Step 8). Introduce the middle boiling component in the feed. Locate the side-draw on the tray(s) found at Step 3, and determine the reboiler duty for all configuration(s). Choose the configuration with the lowest reboiler duty as the final configuration (Side-draw flowrate should be determined by a simple mass balance on the column concerning the recoveries required for the two key components) Note: The side-draw flowrate also needs a feasibility study to be exactly determined, which is not the purpose of this work. Hence, an estimate is made by the mass balance on the 
column. Then, in the simulation, the initial guess is varied in order to reach the convergence for all possible configurations.

\section{- Application examples}

Application of the developed framework is demonstrated by three examples. The first case study is a separation of benzene and p-xylene with trace amounts of toluene as an impurity. The second case study is a separation of n-pentane and n-heptane with n-hexane as an impurity. The third one is an industrial rectification column of Inbicon bioethanol plant. To predict the thermodynamic properties of the systems, an appropriate equation of state shall be chosen. In this study, PengRobinson has been chosen as equation of state for modeling the first two systems. In this section, the distillation units are designed based on the methodology above. Then, the first two case studies are compared with the corresponding configurations proposed by classical driving force designs

${ }^{16}$. Throughout this comparison, the number of theoretical stages is assumed to be identical to the value calculated in Algorithm 1 in this study. Hence, the difference of the outcome configuration between driving force and molecular tracking shall be feed and side-draw locations. Different configurations result in different reboiler and condenser duties. For the third case study the configuration proposed by molecular tracing concept is compared to the results reported in ${ }^{21}$. 


\section{- Example 1: Mixture of benzene and p-xylene with toluene as impurity (BTX system)}

Benzene, toluene, and p-xylene are major upstream components in petrochemical processes. These components are used for the production of many intermediate and final products in chemical industries. Therefore, a large production of these three components is required. The mixture containing these three components is slightly non-ideal. Details of the feed mixture and designs are given in Table 1. Since the boiling point of the components in this system is not very high, the operating pressure of the column is set to $101.325 \mathrm{kPa}^{22}$.

\section{- Example 2: Mixture of n-Pentane and n-heptane with n-hexane as an impurity (PHH system)}

${ }^{16}$ have designed a distillation unit for a mixture of n-pentane, n-heptane, and n-hexane by using the driving force-based approach. Since the mixture deviation from ideality is small, it is a notable example for this study. In this case study, in order to design the column using molecular tracking, it is considered that n-hexane is at infinite dilution. The operating pressure of the unit is 506.625 $\mathrm{kPa}$. 
Using the BTX data, the molecular tracking based design method proposes a configuration of a distillation unit in which the column contains 16 theoretical stages, the feed is located at tray 7 from the top, and the side-draw is located at tray 8 . The reflux ratio of the column shown by the Aspen HYSYS simulation is 2.39 , while $R R / R R_{\min }=1.4$. The recoveries of benzene in the distillate and p-xylene in the bottom stream are $98.36 \%$ and $92.85 \%$ respectively, while $56.26 \%$ of toluene is recovered in the side-draw with corresponding purity of $1.4 \%$. The driving forcebased method for a side-draw distillation (algorithm D2) ${ }^{16}$ proposes a configuration in which the feed is charged to tray 6 with a vapor quality of 39\%, and the side-draw is taken from tray 10 from the top. $99.71 \%$ of benzene is recovered in the distillate product, and $90.99 \%$ of p-xylene is recovered in the bottom stream. The recovery of toluene in the side-draw $58.35 \%$ with a purity of $1.5 \%$. The reflux ratio validated by the simulation is 2.17 . Given the configuration suggested by consideration of molecular tracking, the reboiler duty of the unit shall be $4.66 \mathrm{MW}$, while the reboiler duty of the configuration proposed by the classical driving force is $6.23 \mathrm{MW}$. The molecular tracking configuration saves the energy required for the reboiler of such a separation task by $25 \%$, while the recoveries of benzene should be compromised by $1.35 \%$.

In this case study, molecular tracking suggests that the side-draw should be located on tray 8, while a validation with Aspen HYSYS software suggests that side-draw has to be located on tray 7 to achieve the lowest column duty. By locating the side-draw at tray 7 , the simulation shows the design parameters as follows: reflux ratio $3.85\left(R R / R R_{\min }=1.4\right)$, n-pentane recovery $94.89 \%$, 
n-heptane recovery $98.37 \%$, and toluene recovery and purity in the side-draw are $53.95 \%$ and $1.8 \%$ respectively.

The configuration proposed by molecular tracking for this separation task is a distillation unit containing 22 theoretical trays in which the feed is located at tray 9 and side-draw is at tray 8, both from the top with a reflux ratio of 3.96. The recoveries of n-pentane in the distillate product and n-heptane in the bottom stream are $96.51 \%$ and $97.38 \%$ respectively. The recovery of n-hexane is $53.61 \%$ with a purity of $1.8 \%$. While the driving force-based method (algorithm D2) ${ }^{16}$ proposes a different configuration in which feed is located at tray 8 with a vapor quality of $-28 \%$ (temperature of the feed would be $92.54{ }^{\circ} \mathrm{C}$ ) and side-draw is located at tray 13 from the top. The reflux ratio of this configuration is 5.04. The light and heavy component recoveries are 99.88\% and $95.31 \%$, while the middle boiling component recovery in the side-draw is $52.70 \%$ with a purity of $1.8 \%$. Given the configuration proposed by molecular tracking for the $\mathrm{PHH}$ case study, the reboiler duty is 7.05 $\mathrm{MW}$, while the duty corresponding to driving force approach is $8.78 \mathrm{MW}$. The reboiler duty is approximately $20 \%$ reduced by using molecular tracking as the design approach for this system with a higher concentration of n-hexane in side-draw. However, the benzene recovery rate is compromised by $1.25 \%$.

\section{- Example 3: Rectification column of Inbicon bioethanol plant}

The Inbicon demonstration plant (Kalunborg, Denmark) has started supplying bioethanol as a fuel additive since $2009^{21}$. The bioethanol plant contains pretreatment, liquefaction, fermentation, and 
purification. The purification unit is a train of distillations consists of three columns in series. In order to obtain anhydrous ethanol, water is then removed by a molecular sieve. Continuous operation is carried out by using two molecular sieves in shifted dehydration and degeneration modes ${ }^{21}$. The first distillation column (COL-1) is a stripper column to remove ethanol from viscous fermentation broth by using steam, while the second column (COL-2) is the aldehyde column. The light impurities are removed as the top product in this column. The third column (COL-3) is the rectification column with side-draw. The purpose of this column is to remove the remaining water from the bottom of the column. Fuel oil (heavy alcohols) should be removed with side-draw at a tray between the distillate and bottom products. Ethanol is removed in distillate product at its azeotropic point with water. ${ }^{21,23}$ provide more details of the process. In this study, COL-3 has been analyzed to find the possible side-draw locations for the removal of the heavy alcohols. Given the design parameters of the column in ${ }^{21}\left(N_{T}=40, N_{F}=30, P_{D}=\right.$ 290.802 $\left.\mathrm{kPa}, P_{B}=309.041 \mathrm{kPa}\right)$ and $U N I F A C$ as the thermodynamic package, a column is simulated for the binary mixture of ethanol and water (considering that each impurity has a mass composition of $0.0001 \mathrm{ppm}$ ) with the relative mass composition of stream-3 in ${ }^{21}$. The column is simulated such that the purities of top and bottom products meet the required specifications of the plant. Table 3 represents the simulated column operating conditions. The summary of the column product streams is illustrated in Table A.1. The bottom stream is pure water, while the distillate stream contains ethanol at its azeotropic point with water. 
By using the K-value profiles of the heavy alcohols in the simulated column, the liquid, and vapor internal flowrates the probability profile is generated for each of those alcohols. Fig. 22 represents this profile. Based on the molecular tracking concept, the possible locations of side-draw in this column are 29, 30, 31, and 32 (from top). In order to determine the reboiler duty in each possible configuration, the impurities are defined as reported in ${ }^{21}$. In that study, the authors have found the side-draw location at tray 16 from bottom (25 from top), while molecular tracking misses that tray it shows other possibilities of the side-draw location. Molecular tracking slightly improves the energy consumption of the column and the recovery of the higher saturated mono alcohols (HSMA) molecules from the side-draw.

Table A.2 provides the detailed result of the column simulation in Aspen Plus software by putting side-draw at the trays found by molecular tracking and the tray reported by ${ }^{21}$. Fig. 23 shows that the maximum recovery of the heavy alcohols takes place by putting the side-draw at tray 28 . While the minimum reboiler duty takes place when side-draw is located on tray 31 and the recovery of the heavy alcohols would become slightly lower than the maximum. Hence, the application of molecular tracking on the Inbicon rectification column, suggests a configuration as such that $N_{S}=$ 31 with $Q_{R}=0.91 M W .{ }^{21}$ has shown the column configuration such that the side-draw should be located at tray 16 from bottom $\left(N_{S}=25\right)$ with $Q_{R}=0.91 \mathrm{MW}$. However, the simulation of such configuration in Aspen plus shows that the reboiler duty would be $Q_{R}=0.92 \mathrm{MW}$, which is $0.28 \%$ higher than the value reported in that study for the operating column. Although the application of 
molecular tracking shows a different side-draw location compared to the operating column, it maintains the column energy consumption.

\section{- Further analysis}

In this section, another approach is used to generate VLE data of the impurities of which their thermodynamic properties may not be easily determined by thermodynamic models such as a mixture containing long-chain hydrocarbons or fatty acids. The approach is based on density functional theory. Moreover, a sensitivity analysis of the thermodynamic properties of both systems is carried out to evaluate the sensitivity of the side-draw location to the relative volatility of the mixture components.

\section{- Determination of VLE with computational chemistry-based thermodynamics}

In many feed streams, impurities exist at trace levels of concentration. Often lack of information on the properties of such compounds in the system can make the design of the unit of operation extremely difficult. Hence a method is required in these cases to provide sufficient properties of that compound based on the existing data. In this study, the VLE of the two case studies is regenerated by using computational methods in chemistry, COSMOtherm ${ }^{24,25}$. It is possible to use our molecular tracking method using thermodynamics based on first principles rather than with equation of state methods (Peng-Robinson thus far); we will as an example present the VLE of the

two case studies using the conductor-like screening model for real solvents (COSMO-RS) ${ }^{26,27}$, as implemented in COSMOtherm. One advantage of using computational chemistry for generating 
thermodynamics data is that it can be used for components in any combination, which may not be parameterized for equations of state methods.

For any novel compounds, density functional theory (DFT) will need to be utilized to generate this input, but these quantum chemistry calculations, though computationally heavy, only need to be carried out once.

The benzene, p-xylene, and n-pentane, n-heptane vapor-liquid equilibrium data (from BTX and PHH application examples) are regenerated with COSMOtherm in Fig. 24, to show how the VLE differs compared to the data generated with the Peng-Robinson equation of state. As can be seen, the benzene, p-xylene is fairly close in both methods, but there is a clear difference with n-pentane, n-heptane.

\section{- Sensitivity Analysis}

Computer-aided design approaches depend strongly upon thermodynamic and properties ${ }^{28}$. Hence, these properties are important sources of input variabilities throughout calculations. In this study, a sensitivity analysis is carried out based on the thermodynamic properties. Binary distillation is designed for the binary mixture of key components using binary VLE data. The sensitivity analysis is made to the relative volatility $\left(\alpha_{i, j}\right)$ of that hypothetical mixture. Perturbations of $5 \%$ and $10 \%$ are applied to the relative volatilities of both case studies. Subsequently, the side-draws of both examples are relocated regarding these hypothetical miscalculations. 
The relative volatility of benzene and p-xylene in the BTX example at $101.325 \mathrm{kPa}$ can be calculated from the VLE data. By changing this value, the new probability profile of toluene in the system can be generated and plotted, as illustrated in Fig. 25(a) for $\pm 5 \%$ and $\pm 10 \%$. For all perturbations, the probability profile remains identical to the one derived from the model

The same analysis is carried out for the second case study of the PHH mixture. Moderate variations in the relative volatility between n-heptane and n-heptane show only small changes in the probability profile of n-hexane in the column. As it is represented in Fig. 25(b), all probability profiles are identical.

\section{- Conclusion}

In this study, a systematic method is developed for the design of side-draw distillation units based on the concept of molecular tracking, integrated with the conventional methods of distillation design such as McCabe-Thiele, driving force-based method or other existing methods. The application of the framework has been demonstrated through two case studies of ternary mixtures, BTX and PHH mixtures, and a case study of a multi-component mixture in which the middle boiling components are at trace concentration levels. As the component at infinite dilution hardly affects the thermodynamic properties of the system, a column is at first designed for the separation of key components that follows the final specifications. Thereafter, the impurity is introduced to the column, and the side-draw is located at the tray with a maximum concentration of the middle boiling component, corresponding to minimum column duty. An analysis has been carried out to 
show the deviation of the column design by molecular tracking from a similar column designed by driving force-based method. It has been shown that the case studies designed with molecular tracking do not operate at maximum driving force but have lower column duty. The application examples in this study, show that molecular tracking guarantees optimal design configurations for side-draw distillations with middle boiling components at infinite dilution. The sensitivity of side draw locations to the relative volatility of the key components has verified that molecular tracking results will not be strongly affected by moderate variations of that property. As future studies over molecular tracking concept are to solve an integrated design and control problem for side-draw distillation units.

\section{Notation}

$\begin{array}{ll}B & \text { Bottom stream flowrate }(\mathrm{mol} / \mathrm{s}) \\ \text { BTX } & \text { A mixture of benzene, toluene, and p-xylene } \\ C C & \text { The ratio of reflux ratio and the minimum reflux ratio } \\ D & \text { Distillate stream flowrate }(\mathrm{mol} / \mathrm{s}) \\ D_{x} & \text { Liquid composition of the light key corresponding the } \\ & \text { maximum driving force } \\ D_{y} & \text { Maximum driving force value }(\mathrm{mol} / \mathrm{mol}) \\ E & \text { Murphree efficiency } \\ F & \end{array}$


HSMA Higher saturated mono alcohols

K

The ratio between the vapor and liquid composition

of a component

Internal liquid flowrate in rectifying section of the

$L$

column $(\mathrm{mol} / \mathrm{s})$

Internal liquid flowrate in stripping section of the

column $(\mathrm{mol} / \mathrm{s})$

$N_{F} \quad$ Feed tray number from top

$N_{S} \quad$ Side-draw tray number from top

$N_{T} \quad$ Number of theoretical trays

$P \quad$ Pressure $(\mathrm{Pa})$

PHH A mixture of n-pentane, n-hexane and n-heptane

$Q \quad$ Duty $(M W)$

$q \quad$ Feed vapor quality

$R R \quad$ Reflux ratio

$R R_{\min } \quad$ Minimum reflux ratio

$S \quad$ Side-draw flowrate $(\mathrm{mol} / \mathrm{s})$

$T-x y \quad$ Vapor-liquid equilibrium temperature profile 


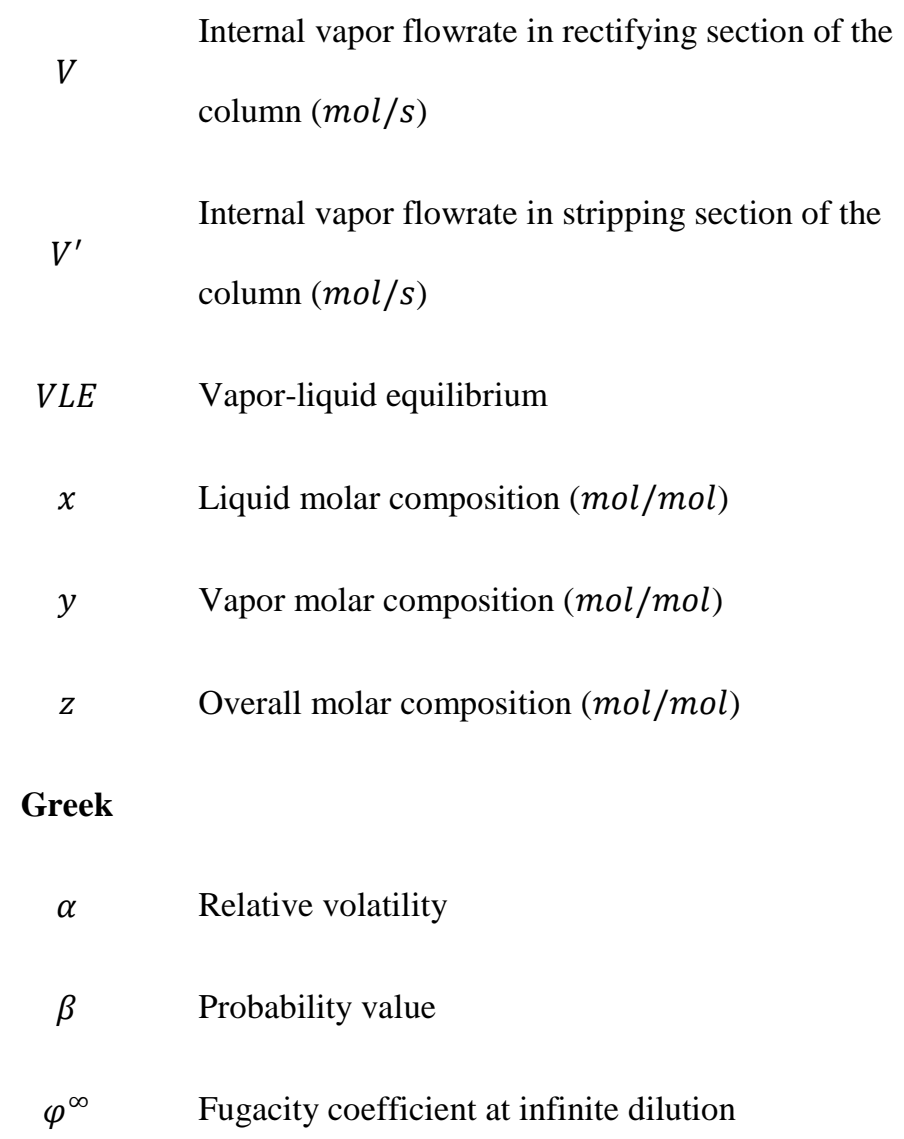

\section{Greek}

$\alpha \quad$ Relative volatility

$\beta \quad$ Probability value

$\varphi^{\infty} \quad$ Fugacity coefficient at infinite dilution

\section{Subscripts}

$i \quad$ component identification

j component identification

MB Middle boiling component

\section{Superscripts}
F $\quad$ Feed
l Liquid phase 
$\boldsymbol{n} \quad$ Tray number identification

$\boldsymbol{S} \quad$ Side-draw

$\boldsymbol{v} \quad$ Vapor phase

\section{List of Figure Captions}

Fig. 1 Side-stream distillation column configurations; (a) side-stream in rectifying section and a (b) side-stream in stripping section.

Fig. 2 (a) Side-draw distillation column of a ternary mixture with hypothetical molecular pathways, (b) number of molecular passes versus stage number for light key and heavy key components, and (c) number of passes of middle boiling component versus stage number ${ }^{1}$.

Fig. 3 Overview of the design procedure using molecular tracking concept

Fig. 4 VLE diagram of benzene, p-xylene at $101.325 \mathrm{kPa}$

Fig. 5 Benzene, p-xylene driving force diagram at $101.325 \mathrm{kPa}$

Fig. 6 Reflux ratio and minimum reflux ratio on driving force diagram of benzene and p-xylene

Fig. 7 McCabe-Thiele diagram for benzene, p-xylene at $101.325 \mathrm{kPa}, \mathrm{RR}=1.02$ 
Fig. 8 T-xy diagram and temperature profile of the column for benzene and p-xylene. Dashes denote tray compositions

Fig. 9 Distillation unit for benzene and p-xylene

Fig. 10 Probability profile of toluene inside the column

Fig. 11 Trays in which toluene probability is $50 \%$

Fig. 12 Reboiler duty of the BTX column versus side-draw location

Fig. 13 VLE diagram of n-pentane and n-heptane at $506.625 \mathrm{kPa}$

Fig. 14 Driving force diagram of n-pentane and n-heptane at $506.625 \mathrm{kPa}$

Fig. 15 Reflux ratio and minimum reflux ratio on driving force diagram of n-pentane and n-heptane

Fig. 16 McCabe-Thiele diagram for n-pentane, n-heptane at $506.625 \mathrm{kPa}, \mathrm{RR}=1.33$

Fig. 17 T-xy diagram and temperature profile of the column for n-pentane and n-heptane. Vertical lines show the theoretical trays

Fig. 18 Distillation unit for n-pentane and n-heptane

Fig. 19 Probability profile of n-hexane inside the column

Fig. 20 Trays in which n-hexane probability is $50 \%$.

Fig. 21 Reboiler duty of the PHH column versus side-draw location

Fig. 22 Probability profiles of the heavy alcohols: 1-propanol, 1 butanol, 2-butanol, 2-methyl-1-propanol, 2methyl-1-butanol, 3-methyl-1-butanol in the column

Fig. 23 Reboiler duty and HSMA recovery in the side-draw at different locations of side-draw 
Fig. 24 VLE diagrams of (a)benzene, p-xylene and (b)n-pentane, n-heptane system using Peng-Robinson and COSMOtherm

Fig. 25 Probability profiles of (a) toluene in BTX column and (b) n-hexane in PHH column with perturbations on the relative volatility between the two key components in the system

\section{References}

1. Nazemzadeh N, Udugama IA, Taube MA, Abildskov J, Mansouri SS. Molecular tracking: A novel approach for multicomponent distillation column design. In: Computer Aided Chemical Engineering. Vol 46. ; 2019:313-318.

2. Ma Y, Luo Y, Zhang S, Yuan X. Simultaneous optimization of complex distillation systems 
and heat integration using pseudo-transient continuation models. Comput Chem Eng. 2018;108:337-348.

3. Seader D, Henley EJ, Roper DK. Separation process principles. Choice Rev Online. 1999;36(09):36-5112-36-5112.

4. Nikačević NM, Huesman AEM, Van den Hof PMJ, Stankiewicz AI. Opportunities and challenges for process control in process intensification. Chem Eng Process Process Intensif. 2012;52:1-15.

5. Rasmussen JB, Mansouri SS, Abildskov J, Huusom JK. A mass and energy balance stage model for cyclic distillation. AIChE J. 2020;(March):1-15.

6. Nielsen RF, Huusom JK, Abildskov J. Driving Force Based Design of Cyclic Distillation. Ind Eng Chem Res. 2017;56(38):10833-10844.

7. Andersen BB, Nielsen RF, Udugama IA, Papadakis E, Gernaey K V., Huusom JK, Mansouri SS, Abildskov J. Integrated Process Design and Control of Cyclic Distillation Columns. IFAC-PapersOnLine. 2018;51(18):542-547.

8. Mansouri SS, Sales-Cruz M, Huusom JK, Gani R. Systematic integrated process design and control of reactive distillation processes involving multi-elements. Chem Eng Res Des. 2016;115:348-364.

9. Mansouri SS, Sales-Cruz M, Huusom JK, Gani R. Integrated Process Design and Control 
of Multi-element Reactive Distillation Processes. IFAC-PapersOnLine. 2016;49(7):735740.

10. Mansouri SS, Sales-Cruz M, Huusom JK, Woodley JM, Gani R. Integrated process design and control of reactive distillation processes. IFAC-PapersOnLine. 2015;48(8):1120-1125.

11. Tula AK, Wang J, Chen X, Mansouri SS, Gani R. ProCACD: A computer-aided versatile tool for process control. Comput Chem Eng. 2020;136:106771.

12. Mansouri SS, Huusom JK, Gani R, Sales-Cruz M. Systematic integrated process design and control of binary element reactive distillation processes. AIChE J. 2016;62:3137-3154.

13. Tedder DW, Rudd DF. Parametric studies in industrial distillation: Part I. Design comparisons. AIChE J. 1978;24(2):303-315.

14. Rooks RE, Malone MF, Doherty MF. A Geometric Design Method for Side-Stream Distillation Columns ${ }^{\dagger}$. Ind Eng Chem Res. 1996;35(10):3653-3664.

15. Glinos K, Malone M. Design of Sidestream Distillation Columns. Ind Eng Chem Process Des Dev. 1985;24(3):822-828.

16. Bek-Pedersen E, Gani R. Design and synthesis of distillation systems using a driving-forcebased approach. Chem Eng Process Process Intensif. 2004;43(3):251-262.

17. Meidanshahi V, Adams TA. Integrated design and control of semicontinuous distillation systems utilizing mixed integer dynamic optimization. Comput Chem Eng. 2016;89:172- 
183.

18. Nazemzadeh N, Udugama IA, Nielsen RF, Meyer K, Perez-Cisneros ES, Sales-Cruz M, Huusom JK, Abildskov J, Mansouri SS. 6. Graphical tools for designing intensified distillation processes: Methods and applications. In: Process Intensification. De Gruyter; 2019:145-179.

19. Maat CA. Molecular Tracking-A New Way of Analyzing Distillation Columns. In: 2017 Spring Meeting and 13th GLobal Congress on Process Safety, AIChE. ; 2017.

20. Lopez-Arenas T, Mansouri SS, Sales-Cruz M, Gani R, Pérez-Cisneros ES. A Gibbs energydriving force method for the optimal design of non-reactive and reactive distillation columns. Comput Chem Eng. 2019;128:53-68.

21. Bisgaard T, Mauricio-Iglesias M, Huusom JK, Gernaey K V., Dohrup J, Petersen MA, Abildskov J. Adding Value to Bioethanol through a Purification Process Revamp. Ind Eng Chem Res. 2017;56(19):5692-5704.

22. Kim YH. Energy Savings in the Benzene-Toluene-Xylene Separation Process Using an Extended Divided-Wall Column. Chem Eng Technol. 2016;39(12):2312-2322.

23. Larsen J, Østergaard M, Thirup L. Inbicon makes lignocellulosic ethanol a commercial reality. Biomass and Bioenergy. 2012;46:36-45.

24. COSMOtherm. Published online 2019. 
25. Eckert F, Klamt A. Fast Solvent Screening via Quantum Chemistry: COSMO-RS Approach. AIChE J. Published online 2002.

26. Klamt A. Conductor-like screening model for real solvents: A new approach to the quantitative calculation of solvation phenomena. J Phys Chem. Published online 1995.

27. Klamt A, Jonas V, Bürger T, Lohrenz JCW. Refinement and parametrization of COSMORS. J Phys Chem A. Published online 1998.

28. Mathias PM. Effect of VLE uncertainties on the design of separation sequences by distillation - Study of the benzene-chloroform-acetone system. Fluid Phase Equilib. 2016;408:265-272. 
(b)
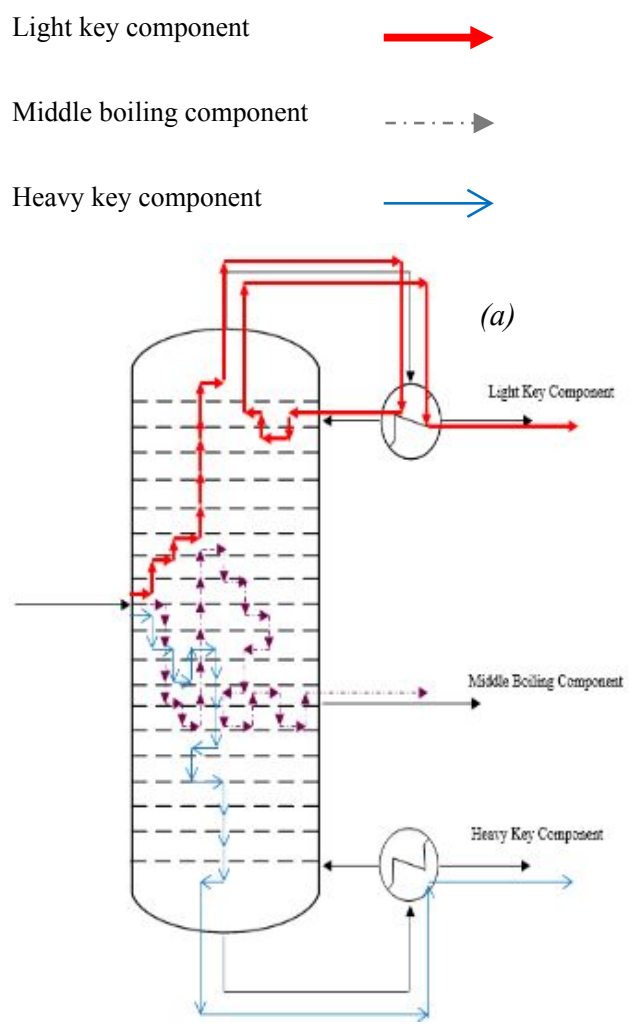
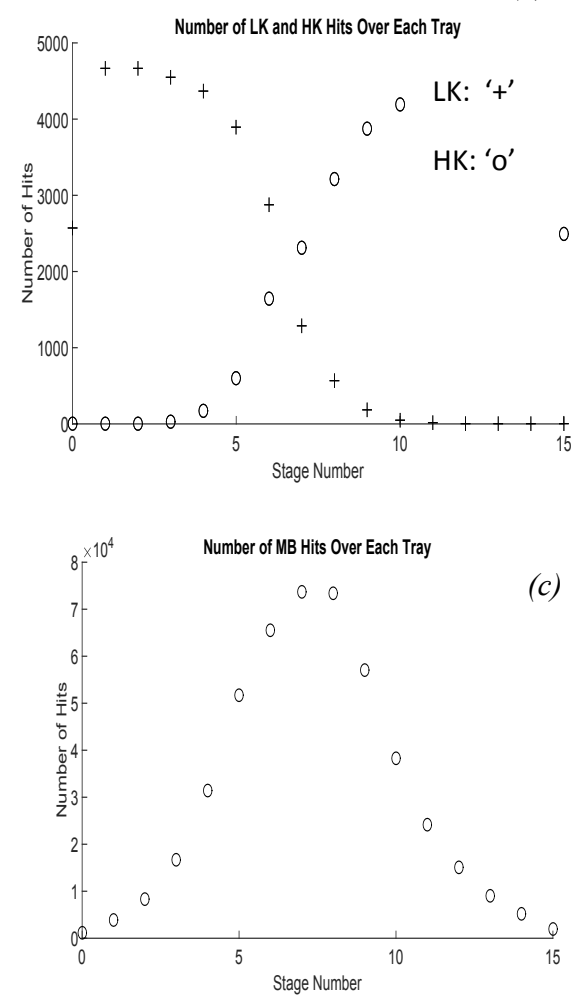

Fig. 2: (a) Side-draw distillation column of a ternary mixture with hypothetical molecular pathways, (b) number of molecular passes versus stage number for light key and heavy key components, and (c) number of passes of middle boiling component versus stage number ${ }^{1}$.

This article is protected by copyright. All rights reserved. 


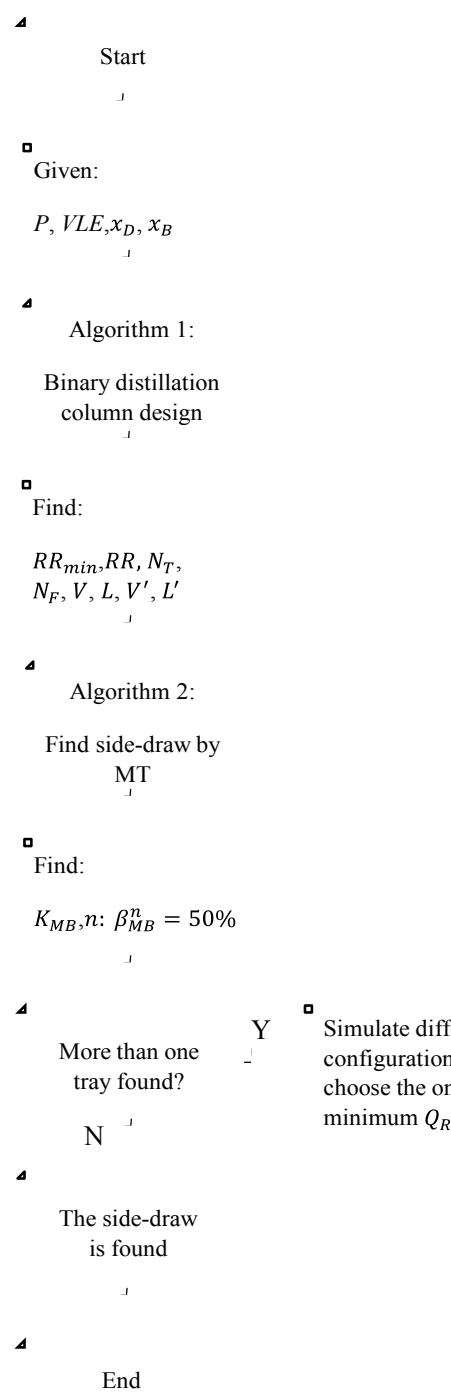

Fig. 3: Overview of the design procedure using molecular tracking concept

This article is protected by copyright. All rights reserved. 
Table 1: Datasheet of the BTX case study

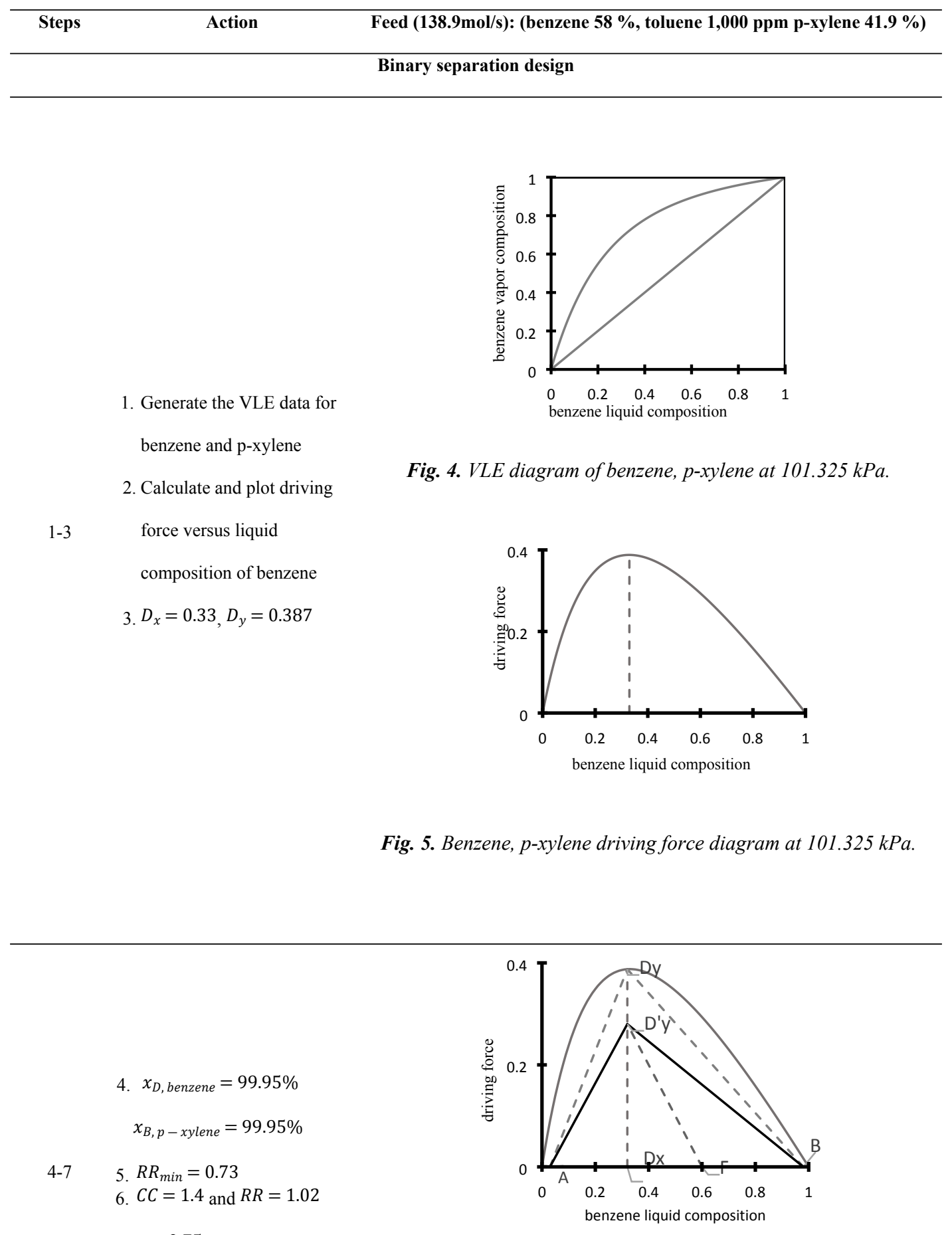

Fig. 6. Reflux ratio and minimum reflux ratio on driving force

diagram of benzene and p-xylene. 


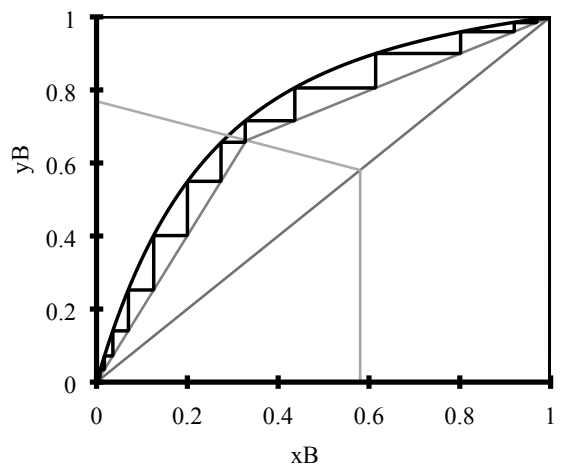

8. McCabe-Thiele diagram, number of stages and feed 8,9 location $N_{T}=16, N_{F}=7$

9. T-xy diagram

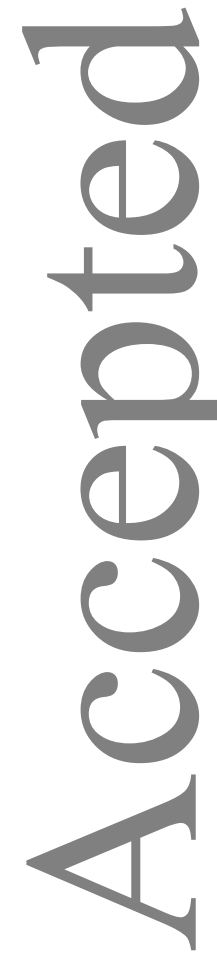

Fig. 7. McCabe-Thiele diagram for benzene, p-xylene at 101.325 $k P a, R R=1.02$.

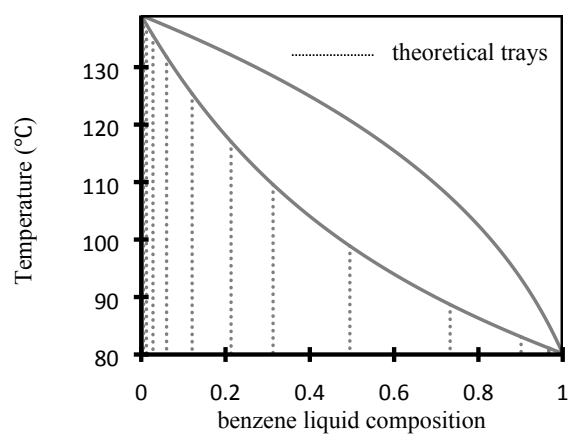

Fig. 8. T-xy diagram and temperature profile of the column for benzene and p-xylene. Dashes denote tray compositions.

$$
\begin{aligned}
& L=82 \mathrm{~mol} / \mathrm{s} \\
& V=161.91 \mathrm{~mol} / \mathrm{s} \\
& L^{\prime}=116.73 \mathrm{~mol} / \mathrm{s} \\
& V^{\prime}=57.74 \mathrm{~mol} / \mathrm{s}
\end{aligned}
$$

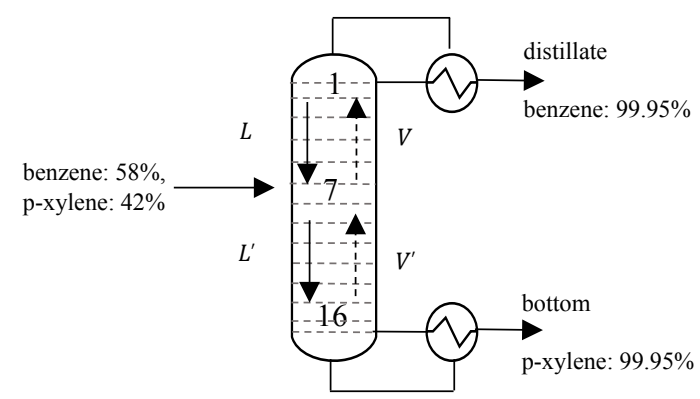

Fig. 9. Distillation unit for benzene and p-xylene. 
1. Calculate K-value profile for toluene.

1-2 2. Calculate probability profile and draw the probability diagram

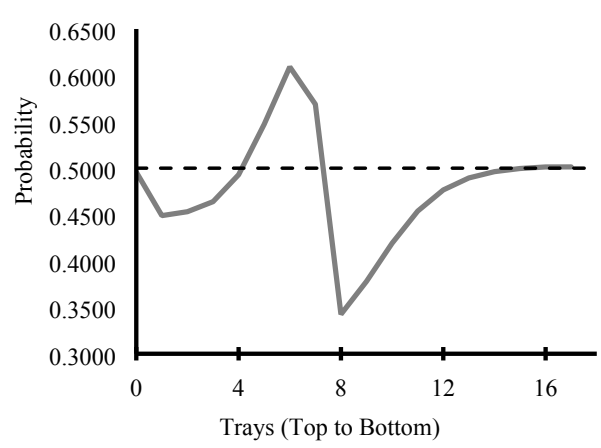

Fig. 10. Probability profile of toluene inside the column.

3. Trays with $50 \%$ probability can be $4,5,7$, 8.

4. The number of possible side-draw locations are more than one tray

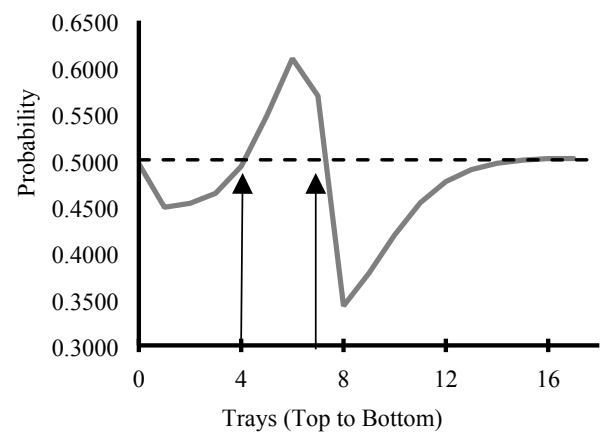

Fig. 11. Trays in which toluene probability is 50\%.

5. Simulate the column and choose the tray with minimum reboiler duty as the side-draw location.

$$
\begin{aligned}
& N_{S}=8 \\
& S=5.55 \mathrm{~mol} / \mathrm{s}
\end{aligned}
$$

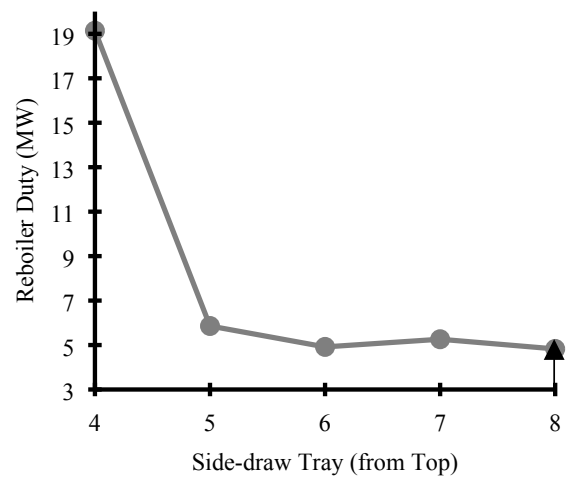

Fig. 12. Reboiler duty of the BTX column versus side-draw location. 
Table 2: Datasheet of PHH case study

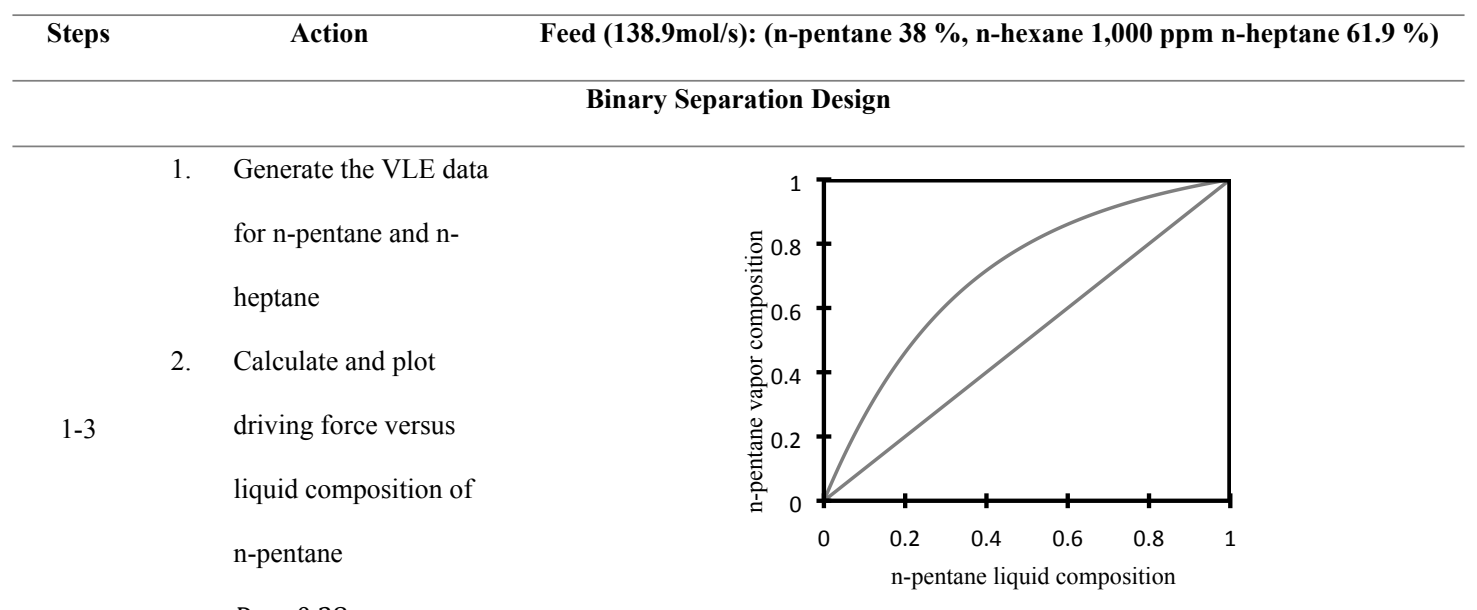

3. $D_{x}=0.38$ and

$D_{y}=0.317 \quad$ Fig. 13. VLE diagram of n-pentane and n-heptane at $506.625 \mathrm{kPa}$

This article is protected by copyright. All rights reserved. 


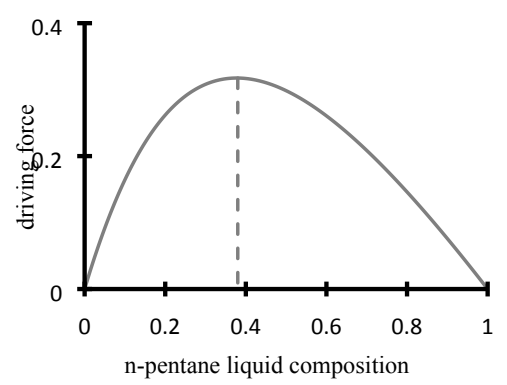

Fig. 14. Driving force diagram of n-pentane and n-heptane at

$506.625 \mathrm{kPa}$

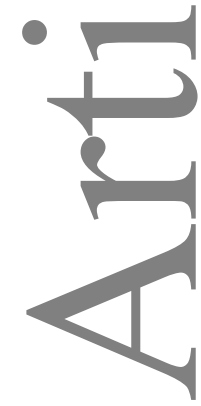

4. $x_{D, n-\text { pentane }}=99.95 \%$

$x_{B, n-\text { heptane }}=99.95 \%$

4-7 5. $R R_{\text {min }}=0.95$

6. $C C=1.4$ and $R R=1.33$

7. $q=0$

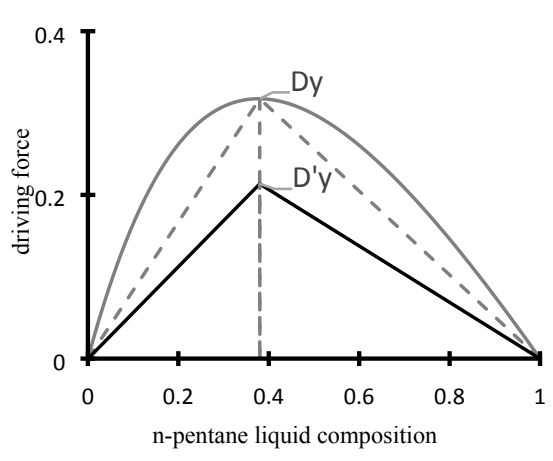

Fig. 15. Reflux ratio and minimum reflux ratio on driving force diagram of n-pentane and n-heptane.

8. Draw McCabe-Thiele diagram and find the number of stages and feed

8,9 location $N_{T}=22, N_{F}=9$

9. T-xy diagram

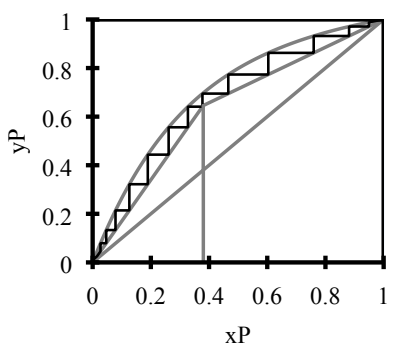

Fig. 16. McCabe-Thiele diagram for n-pentane, $n$-heptane at 506.625

$k P a, R R=1.33$. 


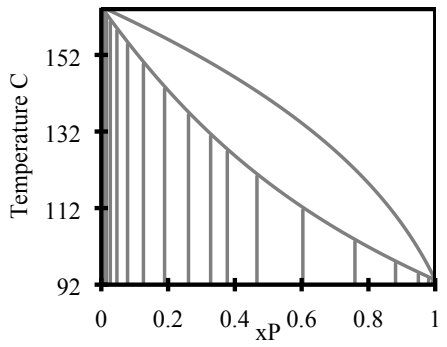

Fig. 17. T-xy diagram and temperature profile of the column for $n$ pentane and n-heptane. Vertical lines show the theoretical trays.

10

$$
\begin{aligned}
& L=70.24 \mathrm{~mol} / \mathrm{s} \\
& V=123.05 \mathrm{~mol} / \mathrm{s} \\
& L^{\prime}=209.13 \mathrm{~mol} / \mathrm{s} \\
& V^{\prime}=123.05 \mathrm{~mol} / \mathrm{s}
\end{aligned}
$$

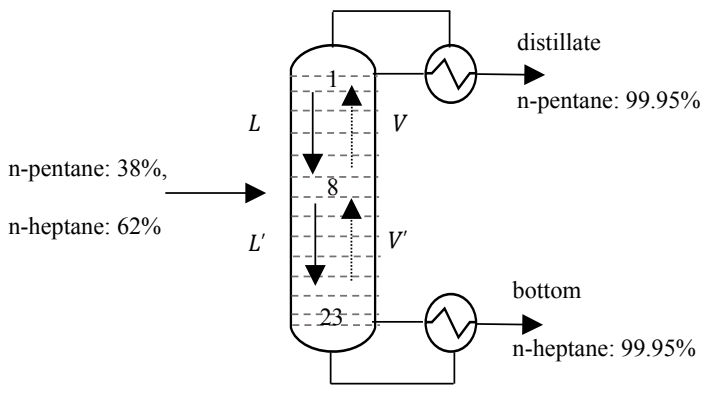

Fig. 18. Distillation unit for n-pentane and n-heptane.

Find side-draw location using molecular tracking

1. Calculate the K-value profile for n-hexane.

$1-2$

2. Calculate probability profile and draw the probability diagram

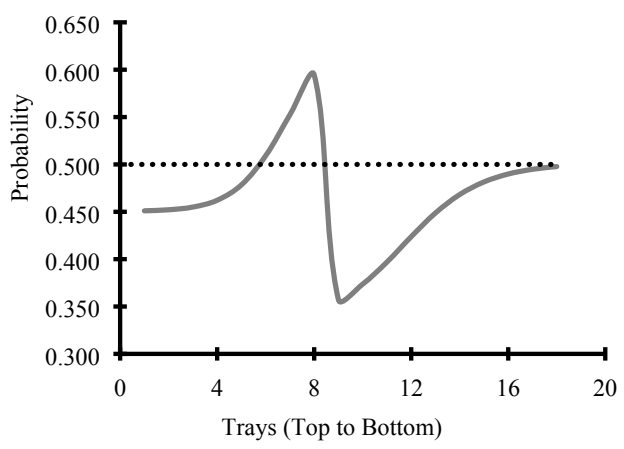

Fig. 19. Probability profile of n-hexane inside the column. 
3. Trays with $50 \%$

probability are $5,6,8$,

and 9 .

$3-4$

4. The number of possible side-draw locations are more than one tray

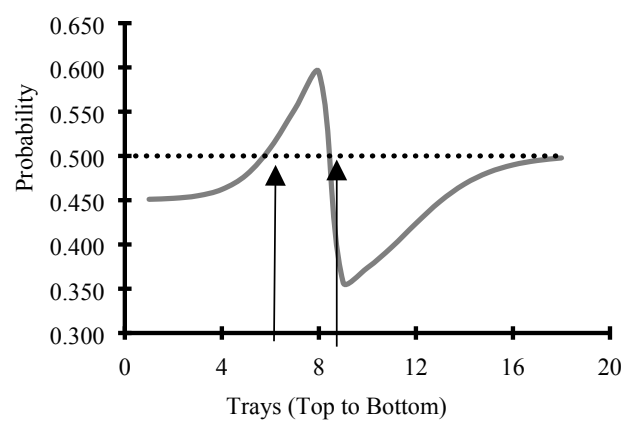

Fig. 20. Trays in which $n$-hexane probability is $50 \%$.

5. Simulate the column and choose the tray with minimum reboiler duty as the side-draw location.

$$
N_{S}=7
$$

$S=4.16 \mathrm{kmol} / \mathrm{h}$

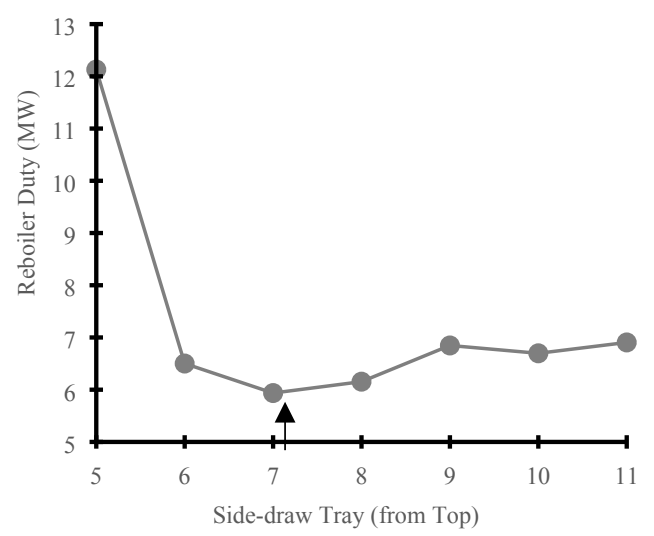

Fig. 21. Reboiler duty of the PHH column versus side-draw location.

Table 3: Operating conditions of the rectification column for the binary mixture of water and ethanol

\begin{tabular}{ccc}
\hline Variable & Unit & Value \\
\hline $\boldsymbol{E}$ & - & 0.55 \\
$\boldsymbol{Q}_{\boldsymbol{F}}$ & $M W$ & 0.005 \\
$\boldsymbol{Q}_{\boldsymbol{R}}$ & $M W$ & 0.95 \\
$\boldsymbol{Q}_{\boldsymbol{C}}$ & $M W$ & -8.87 \\
$\boldsymbol{R} \boldsymbol{R}$ & - & 12.5 \\
$\boldsymbol{B R}$ & - & 1.62 \\
\hline
\end{tabular}

This article is protected by copyright. All rights reserved. 

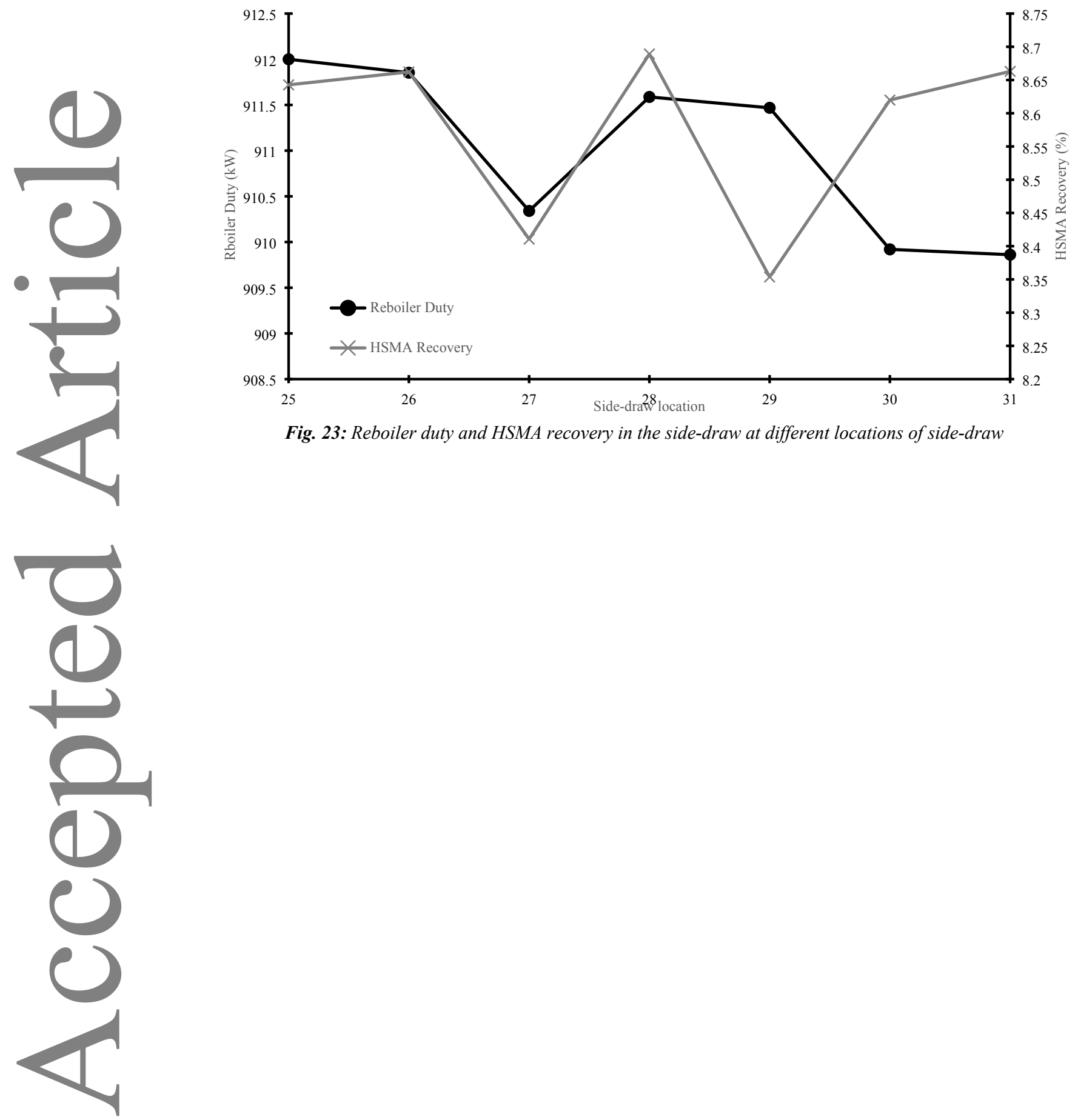

Fig. 23: Reboiler duty and HSMA recovery in the side-draw at different locations of side-draw 

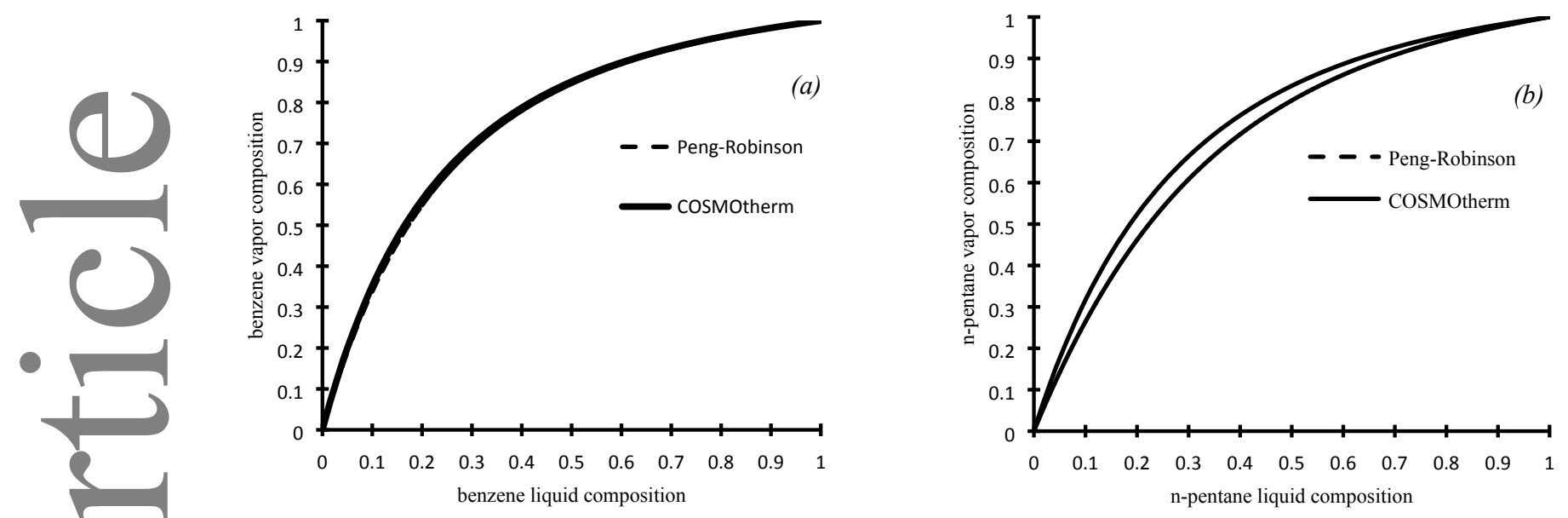

Fig. 24: VLE diagrams of (a)benzene, p-xylene and (b)n-pentane, $n$-heptane system using Peng-Robinson and COSMOtherm 


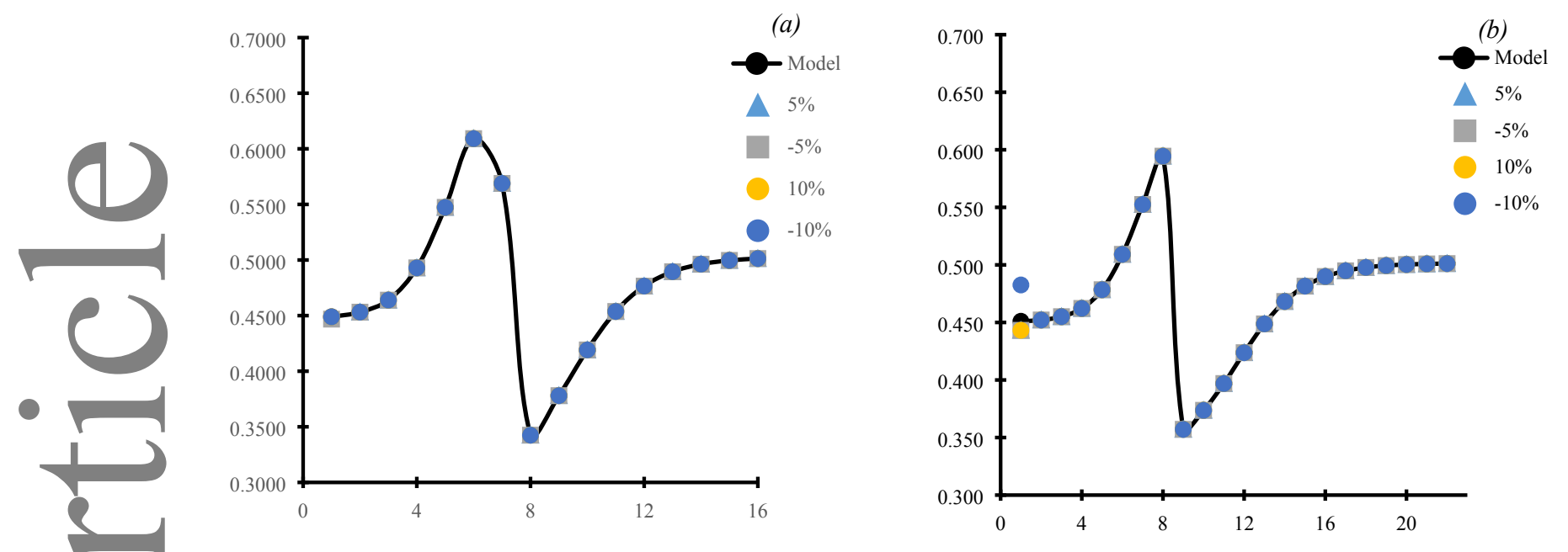

Fig. 25: Probability profiles of (a) toluene in BTX column and (b) $n$-hexane in PHH column with perturbations on the relative volatility between the two key components in the system 